\title{
¿Va el cine colombiano hacia su madurez? Análisis de 10 años de ley de cine en Colombia*
}

\author{
Jerónimo Rivera-Betancur ${ }^{* *}$
}

Recibido: mayo 20 de 2014 - Aceptado: septiembre 13 de 2014

\section{Resumen}

Este artículo pretende hacer una radiografía del estado actual de la cinematografía colombiana a la luz de los modelos de producción, la legislación existente, las temáticas abordadas y la formación de realizadores. Para lograrlo, es importante considerar a todos los sectores involucrados en esta industria: distribuidores, exhibidores, productores, patrocinadores y Estado.

El análisis parte de evaluar las condiciones de taquilla en su relación costobeneficio, la cantidad de estrenos nacionales frente a los internacionales, las políticas de fomento estatal a cada una de las etapas de la realización y comercialización de una película, y los reconocimientos internacionales obtenidos por películas colombianas. El período estudiado es el posterior a la Ley de Cine 814 de 2003, por lo que hablaremos de 2003-2013 como un balance de la primera década de aplicación de esta ley que ha impulsado seriamente la cinematografía del país.

Desde la dificultad de definir el cine colombiano como uno solo, se hablará aquí de las películas realizadas en Colombia, haciendo claridad en que esta agrupación incluirá películas de diferente género, temática y tratamiento con la única característica común de ser consideradas por la ley como colombianas. La definición de colombiana es igualmente compleja, pues la ley suele ser laxa en esta definición admitiendo como nacionales a películas producidas en el país o no, con la única condición de que el director y un protagonista sean colombianos. A diez años de la puesta en marcha de la nueva ley del cine, hacemos un balance de lo que esta nueva legislación ha significado para el cine nacional.

Palabras clave: Cine colombiano, ley de cine, políticas culturales, realización cinematográfica

\footnotetext{
* El artículo proviene del análisis de la situación del cine colombiano en estos diez años y de tres proyectos de investigación relacionados con el tema:

1. Personajes, acciones y escenarios del cine colombiano 1990-2005 realizado en la Universidad de Medellín entre 2006 y 2007. Investigadores principales: Ernesto Correa y Jerónimo Rivera, co-investigador: Mauricio Vélez.

2. Narrativas del conflicto armado en el cine colombiano realizado en la Universidad de La Sabana entre 2007 y 2009 Investigador primera etapa: Sandra Ruiz Moreno; investigador segunda etapa: Jerónimo Rivera.

3. Características de los relatos audiovisuales de nuevos realizadores colombianos, caso Opera Prima realizado en la Universidad de La Sabana entre 2010 y 2012. Investigadores: Jerónimo Rivera y Juan Camilo Díaz.

** Docente investigador de la Universidad de La Sabana y director de la Red Iberoamericana de Investigación en Narrativas Audiovisuales-INAV. Correo: jeronimorb@unisabana.edu.co
} 


\title{
Is the Colombian Film Reaching Maturity? Analysis of 10 Years of Film Law in Colombia
}

\begin{abstract}
This article is intended to make a deep description of current condition of Colombian cinematography in Colombia in the light of production models, existing regulations, topics addressed, and producers' education. The analysis starts by evaluating ticket selling concerning cost-benefit, amount of national premieres compared to international ones, policies of the State promotion to each stage of production and marketing of a movie, and international awards obtained for Colombian films. After 10 years of operation of the new film law, this article shows a summary of what this new law represents for the domestic film.
\end{abstract}

Key words: Colombian film; Film Law; cultural policies; film production. 


\section{Introducción}

A pesar de que la primera película colombiana de largometraje fue estrenada hace más de 90 años, el cine colombiano aún no logra consolidarse como industria. Las distintas legislaciones que ha tenido la cultura, y el cine puntualmente, sumadas al intermitente apoyo de la empresa privada y el público nacional no han permitido que Colombia despegue como líder regional y que hacer una película deje de ser para sus productores una gran proeza económica.

Esta situación, no obstante, ha ido cambiando para la industria desde la puesta en marcha de la Ley 814 de 2003 o ley de cine, "Por la cual se dictan normas para el fomento de la actividad cinematográfica en Colombial", que durante diez años ha acompañado a los cineastas colombianos con el objetivo de fomentar y visibilizar el cine que se hace en el país. A pesar de sus detractores, la ley ha permitido aumentar la cantidad de películas y, en muchos casos, la variedad y calidad de las mismas, aunque público y sector empresarial no han dado aún la respuesta que el espíritu de la ley deseaba.

En 2012 el Gobierno expide la Ley 1556 a la que denomina Ley de Filmación y que algunos estamentos denominan Ley de Cine II como si se tratara de una saga de películas. Esta segunda ley, presentada en el marco de los convenios por el tratado de libre comercio con los Estados Unidos (TLC), fue vendida por el Gobierno como una forma de captar recursos extranjeros y posibilitar el intercambio valioso de información y conocimiento entre productoras locales y extranjeras. Esta ley no solo no se relaciona directamente con el espíritu de la Ley de 2003, sino que casi se opone a sus principios, lo que ha generado que el sector se divida entre quienes la consideran una gran oportunidad internacional para la producción cinematográfica colombiana y quienes plantean objeciones relacionadas con su aprobación en el marco del Tratado de Libre Comercio (TLC) entre Colombia y Estados Unidos y su posible favorecimiento a los productores extranjeros en detrimento de la producción nacional.

No analizaremos las implicaciones de esta ley que, además de ser muy reciente, tiene una inspiración que no se relaciona con el sector de la cinematografía nacional, pues pretende "el fomento de la actividad cinematográfica de Colombia, promoviendo el territorio nacional como elemento del patrimonio cultural para la filmación de audiovisuales y a través de estos, la actividad turística y la promoción de la imagen del país, así como el desarrollo de nuestra industria cinematográfica"2.

Por lo anteriormente dicho, nos limitaremos a hablar acerca de la Ley 814, diez años después de su puesta en marcha. Plantear el título como una pregunta nos permite dejar el final abierto, poniendo muchos argumentos sobre la mesa para evaluar si el cine

1 Tomado textual del título de la ley 814 de 2003. Recuperado del sitio web de la Fundación Pro-imágenes en movimiento.

2 Tomado textualmente del texto de la Ley 1556 de 2012 "POR LA CUAL SE FOMENTA EL TERRITORIO NACIONAL COMO ESCENARIO PARA EL RODAJE DE OBRAS CINEMATOGRÁFICAS". De la página de la Cancillería colombiana. Recuperado el 15 de febrero de 2014. 
colombiano va hacia su madurez o si estamos frente a otro momento coyuntural de la historia de este sector en nuestro país.

\section{Antecedentes}

No se puede, por supuesto, hablar de una ley sin hacer un pequeño recorrido histórico por la regulación que la antecedió. Desde 1915, fecha de estreno de María (Máximo Calvo) hasta 2002, en el país se hicieron 270 largometrajes y en solo 10 años, desde la puesta en marcha de la Ley hasta 2013, se realizaron 132. En 1978 el Gobierno nacional creó Focine, compañía de fomento cinematográfico, que funcionó siempre en medio de críticas por su ineficiente gestión y malos resultados. En 15 años de existencia Focine realizó 31 largometrajes, de los cuales solo uno obtuvo rendimientos económicos. El problema no fue solo la falta de rentabilidad de las películas realizadas sino las inmensas deudas que acumuló el Estado por cuenta de películas sin realizar y el otorgamiento de créditos a particulares sin mayores garantías ${ }^{3}$.

En la década de 1990 el cine colombiano experimentó una gran crisis al quedar completamente huérfano de parte del Estado luego de la liquidación de Focine y Colcultura, entidades que soportaron la producción audiovisual en medio de críticas y descalabros económicos; pero que también permitieron la realización de algunos grandes títulos de la filmografía nacional.

A pesar de no contar con el apoyo estatal y de las difíciles condiciones de seguridad de la época ${ }^{4}$, algunos cineastas tomaron el riesgo de realizar películas con resultados muy positivos en algunos casos. Aunque toda la década no pasó de más de una veintena de títulos estrenados, en ese pequeño grupo se encuentran películas tan representativas para la filmografía nacional como: Confesión a Laura (Jaime Osorio, 1990), La estrategia del caracol (Sergio Cabrera, 1993) y La gente de la Universal (Felipe Aljure, 1993).

En 1998 se creó el Fondo Mixto de Promoción Cinematográfica, Proimágenes Colombia ${ }^{5}$, en donde se concertó la Ley de Cine de 2003 que permitió la creación del Fondo para el Desarrollo Cinematográfico (FDC), fuente hasta hoy de más de 50 mil millones de pesos (unos 25 millones de dólares) en estímulos para escritura, producción, distribución, participación internacional, exhibición y conservación de cine nacional; igualmente, la

3 Según un informe especial publicado por la revista Semana en 1993, meses después de la liquidación de Focine, de 36 grandes créditos otorgados en 26 se perdió prácticamente todo el dinero y los largometrajes realizados en el período presentaron un promedio de pérdidas del $80 \%$

4 Los años comprendidos entre 1987 y 1993 son reconocidos por analistas e historiadores como los más violentos de la historia reciente de Colombia. Esta situación fue producto de la guerra frontal que el denominado cartel de Medellín emprendió contra el Estado realizando acciones de terrorismo que tuvieron un fuerte impacto en la población civil.

5 Presidido por el Ministerio de Cultura y del que hacen parte representantes de los ministerios de Educación y de Comunicaciones, la Dirección de Impuestos y Aduanas Nacionales (DIAN), Colciencias, Universidad Nacional, Asociación de distribuidores de películas internacionales, Cine Colombia, Kodak, Patrimonio Fílmico, productores y directores. 
deducción tributaria para las personas y empresas que inviertan en él, sumada a otros beneficios para infraestructuras audiovisuales

La Ley de Cine de 2003 se hizo con la intención de apoyar el cine como elemento cultural imprescindible. El texto de la ley expresa como su objetivo "propiciar un desarrollo progresivo, armónico y equitativo de cinematografía nacional y, en general, promover la actividad cinematográfica en Colombia ${ }^{6 "}$. Parte la ley del reconocimiento de las obras cinematográficas como productos culturales de interés nacional y desde allí se enfatiza en la importancia que tienen los productos cinematográficos para la identidad y el acervo cultural colombiano.

\section{¿Un cine adolescente?}

Un adolescente es alguien que aún no se define claramente; se siente adulto, pero lo tratan como a un niño, un día tiene una idea genial y al siguiente la más desatinada, se esfuerza por demostrar que sabe y puede hacer más cosas de las que él mismo cree, se avergüenza de los cambios que experimenta y todo el tiempo se está comparando con los demás. Aunque no lo demuestre, el adolescente siempre espera la aprobación de los demás... Así parece ser el cine colombiano hoy.

Aunque las cifras presentadas desde la institucionalidad muestran un balance positivo justificado por el aumento de espectadores en películas colombianas, mayor cantidad de producciones y películas exitosas en taquilla, estas cifras deben ser vistas con cuidado, ya que no siempre indican un panorama alentador para todo el cine nacional.

La producción cinematográfica colombiana del año 2012 puede ser un buen ejemplo. Ese año ha quedado registrado históricamente como el más exitoso para la cinematografía colombiana. Antes del último estreno del año7, El paseo 2 (Dago García, 2012), las cifras eran poco alentadoras. La película pasó a convertirse en una de las más taquilleras de la historia nacional llevando a las a salas a más de 1.200.000 espectadores. La película más rentable en las salas colombianas ese mismo año (Los vengadores) sobrepasó ampliamente los dos millones de espectadores, mientras la segunda colombiana más vista (La cara oculta) pasó ligeramente de los seiscientos mil y la quinta más vista de las nacionales (Apaporis) no alcanzó las cuarenta y cinco mil. Con la cantidad de espectadores de la colombiana más vista, la asistencia a cine del público nacional subió hasta el 7,25 \% ese año, poniendo el país porcentualmente por encima de industrias más sólidas como la mexicana y la argentina. Las cifras, por tanto, no permiten apreciar todos los matices.

6 Del capítulo I. Objetivos, competencias especiales y definiciones de la Ley 814 de 2003. Recuperado del sitio web de la Fundación Proimágenes en movimiento.

7 El productor y libretista colombiano Dago García ha acostumbrado al público nacional a esperar el estreno de una película suya cada 25 de diciembre. Sus películas plantean historias cotidianas llevadas al extremo, con una estética kitsch y ridiculización de personajes. Las historias allí presentadas tienen estética y narrativa televisiva y, en general, buena aceptación del público general. En 2013, según el sitio web cinecolombiano.com el 72,59\% de la asistencia de público a películas colombianas se concentró en tres películas de su productora: El paseo, El paseo 2 y El control. 
A un esperanzador 2012, con 22 películas en cartelera le siguió un tímido 2013 en el que los estrenos se redujeron a 17 y la asistencia cayó un 35.74 \% frente al año anterior (2.170.648 espectadores). El porcentaje de participación de cine colombiano en la cartelera de cine nacional se redujo del $7.25 \%$ del 2012 al $4.43 \%$ de la taquilla y del $8.27 \%$ al 5.02 $\%$ de la asistencia ${ }^{8}$.

\section{Participación de las películas nacionales en el total de asistencia en Colombia}

, $2007-2013$

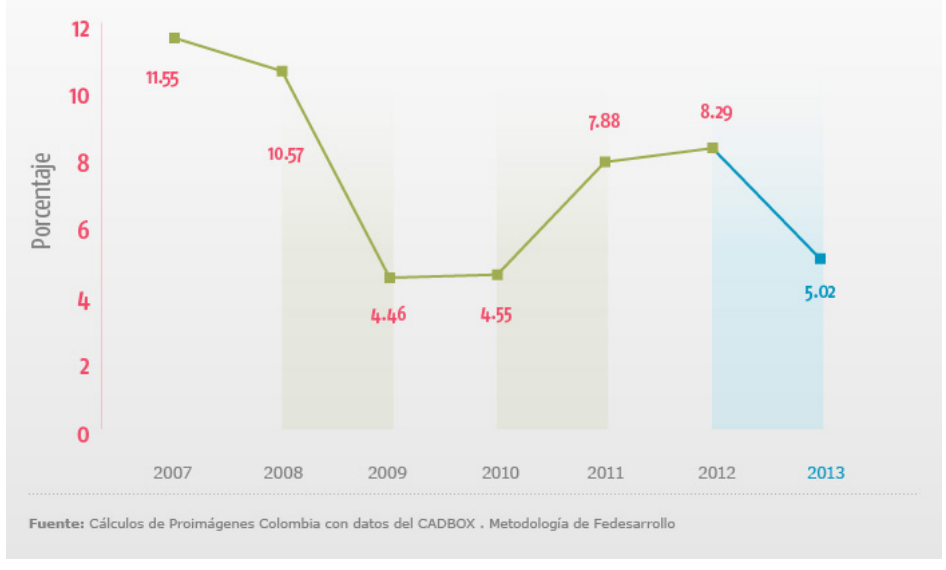

Gráfico 1. Películas nacionales en total de asistencia.

Fuente: Proimágenes Colombia

A esto se suma el hecho de que muchas películas colombianas no llegan siquiera a los diez mil espectadores, que los exhibidores muchas veces no las dejan más de una semana en cartelera y que la escasa promoción hace que muchas de estas películas ni siquiera sean conocidas por el público o no alcancen a ser estrenadas en algunas ciudades del país.

Si algo puede resaltarse en el panorama actual del cine nacional es la diversidad de temas, tratamientos y estéticas de nuestras películas. A pesar de que el público no responde como es debido y la promoción de los títulos nacionales sigue siendo tremendamente desigual, hoy es posible ver en cartelera películas introspectivas en busca de consolidar el cine de autor, historias comerciales que gustan a un amplio público y algunas de género que intentan emular el éxito de las cintas de Hollywood.

\section{Metodología}

Analizar el impacto de la Ley de Cine en la cinematografía nacional requiere no solo del análisis de las cifras, sino de la caracterización de los elementos propicios y adversos que influyen en el desarrollo de una industria cinematográfica colombiana.

8 Cifras de Proimágenes en movimiento. 
Comoquiera que el análisis exclusivamente cuantitativo no arroja resultados confiables; es necesario mirar otras variables relacionadas con la respuesta del público, el desarrollo de la industria cinematográfica en el país y el contenido de las propuestas narrativas.

Partiremos del estudio de las cifras presentadas como balance por la misma Dirección de Cinematografía del Ministerio de Cultura Nacional. El análisis de las cifras se hará a la luz de las variables anteriormente comentadas y de otros análisis realizados en 2013 a propósito de los diez años de la Ley de Cine. La intención de este estudio no es otro que hacer una radiografía que permita definir los aspectos relacionados con una ley que ha dinamizado el sector pero que aún tiene muchos obstáculos a superar hasta lograr que el cine colombiano sea considerado como una industria y que los colombianos se acerquen a las películas producidas en el país sin prejuicios ni asistencialismos. El hilo conductor de este texto no serán, por lo tanto, las cifras ni las estadísticas, sino algunos temas que emergen con fuerza en los distintos análisis y que serán soportados a la luz de las mismas estadísticas.

\section{El cine colombiano 10 años después de la Ley 814}

Partiendo de la dificultad que implica analizar un sector tan complejo como el cinematográfico, en el que intervienen exhibidores, distribuidores, productores, patrocinadores, público y Estado, entre otros, haremos un análisis de algunos de los factores presentados en el foro sobre los diez años de la Ley 814 de 2003 y posteriores análisis realizados en distintos medios de comunicación, así como de las cifras más importantes que presenta Proimágenes en movimiento en sus informes semestrales "Cine en cifras". Estos son los factores más relevantes de diez años de Ley de Cine en Colombia:

\subsection{Cualificación profesional}

Indiscutiblemente, hacer una mayor cantidad de películas por año contribuye a construir industria y a cualificar el recurso humano. La competencia en la prestación de servicios de calidad ha permitido que se especialicen empresas en cada uno de los procesos técnicos y muchos servicios que antes se hacían en el exterior, como todos los relacionados con la posproducción (mezcla de sonido, colorización y otros), ahora se hacen en el país, lo que permite abaratar costos y contribuir al desarrollo de los oficios del cine.

\subsection{Presencia colombiana en cartelera}

La cifra más significativa con relación a la última década de cine colombiano es el incremento de un promedio de tres o cuatro películas anuales a 13,2 llegando en los últimos años a tener entre 17 y 23 películas nacionales en las pantallas. Esta situación ha traído consigo la circunstancia inédita de tener más de una película colombiana al mismo tiempo en pantallas. Aunque esta situación puede considerarse positiva, pues el público reconoce la existencia de un cine nacional, ha faltado una mayor organización en los calendarios de lanzamiento de los títulos nacionales. Después de semanas sin ningún estreno vienen otras de hasta cinco películas nacionales peleando por una pequeña porción de la taquilla.

9 Que pueden consultarse en su página www.pantallacolombia.com 
Es importante entender que en Colombia una película que tenga menos de 300 mil espectadores no obtiene una adecuada rentabilidad. Si partimos de la base de que aun en los últimos años el mercado nacional tiene un promedio de menos de la mitad, concluimos que hacer cine en Colombia aún no es rentable. El problema de fondo es que el mercado colombiano es estrecho y aun películas ganadoras del Oscar obtienen poca respuesta del público.

\subsection{Apoyos a la producción}

Las becas y créditos para la producción de películas han permitido que muchos proyectos que no tendrían oportunidad de realizarse puedan verse en las pantallas. Este aspecto ha sido positivo en películas realizadas desde las regiones, aunque su impacto aún es mínimo y se sigue concentrando la mayoría de las producciones en Bogotá. Adicionalmente, los estímulos tributarios contemplados en la Ley han dado una herramienta fundamental para que los productores busquen apoyo en empresas del sector productivo.

La situación, no obstante, tampoco es ideal. Desde algunos sectores de la crítica se ha atacado el paternalismo del Estado y la poca gestión de los productores al realizar un producto que implica para ellos bajo riesgo, presentándose el caso de desorganización en la gestión e informes de algunos productores frente a los inversionistas, sumado a las bajas expectativas de retribución económica, situación que ha terminado por ahuyentar a empresas que podrían estar interesadas en financiar películas colombianas.

En un informe publicado en su página Cinecolombiano.com, Julio Luzardo plantea sus reparos al modelo de financiación de películas contrastando las que fueron hechas con fondos del FDC con respecto a las que no lo hicieron (a las que denomina "independientes"). En 2013, plantea Luzardo, solo el 12.41 \% de los espectadores del cine colombiano fueron a ver películas financiadas con los recursos estatales (ver gráfico 2).

\begin{tabular}{|c|c|}
\hline Película & Espectadores \\
\hline Amores Peligrosos & 46.786 \\
\hline Lo Azul del Cielo & 19.928 \\
\hline Edificio Royal & 10.937 \\
\hline Cazando Luciérnagas & 7.266 \\
\hline Estrella del Sur & 6.513 \\
\hline La Eterna Noche de las 12 Lunas & 5.972 \\
\hline Don Ca & 4.029 \\
\hline Pescador & 3.526 \\
\hline Pablo's Hippos & 42 \\
\hline TOTAL & 104.999 \\
\hline
\end{tabular}

Gráfico 2: Películas apoyadas por el FDC en 2013 y cantidad de espectadores.

Fuente: Cinecolombiano.com 
Luzardo advierte, además, que la mayoría (67 \%) de las películas exhibidas en estos 10 años fueron producciones que arrancaron sin ningún estímulo de la Ley de Cine. Posteriormente 23 de estas películas recibieron premios de posproducción y promoción a través de Convocatorias del FDC en esta área. Es decir, muchas de las películas estrenadas no recibieron apoyo del Fondo antes de estrenarse en las salas.

\subsection{Apoyos a la formación}

En modalidades distintas a la producción como formación de público, patrimonio e investigación, el Estado ha destinado recursos importantes, pero aún hay una deuda en relación con la catalogación y archivo de esta información, que no se consigue fácilmente. Tal como se afirma en el texto Research on Colombian Cinema: "La investigación sobre cine en Colombia presenta una fuerte semejanza con el cine producido en el país. Ambos están marcados por un desconocimiento de sus antecedentes, ambos son incipientes, pero más relevantes de lo que se cree y ambos pierden su impacto al ser fragmentados e incomunicados"10.

La ley establece que el 70 \% de los recursos del FDC se destine a fomentar la producción y que el 30 \% restante se dedique a apoyar programas de formación, preservación y distribución del cine nacional. Aunque los esfuerzos de formación de públicos aún son aislados y poco representativos, han sido positivos los esfuerzos que diferentes entidades han hecho por recopilar y restaurar el patrimonio fílmico del país y que hoy se pueda acceder a buena parte del cine colombiano en vídeo a bajos costos.

\subsection{Apoyo de los canales de televisión}

Los canales privados de televisión (Caracol y RCN) se han vinculado al proceso del cine, aunque no en las mejores condiciones para los productores de las películas. Reconociendo que el cine pocas veces es industrial pero que el modelo de la televisión sí lo es, el apoyo de la pantalla chica es fundamental para la sostenibilidad del negocio del cine; aunque en la práctica los apoyos muchas veces no van más allá de hacer promoción en los espacios del canal y firmar contratos de difusión desfavorables para los productores.

Algunas de las películas financiadas por los canales son comedias ligeras con estética y narrativa televisivas. El ya mencionado caso de Dago García, quien, además, es directivo de Caracol TV, pone en evidencia que conoce el negocio y llega fácilmente al público. Según Anita de Hoyos"1" "no se trata de hacer lo que hacen Dago o Trompetero, personajes que entre otras cosas tienen sus méritos y son difíciles de imitar. Se trata de reconocer el camino que ellos abrieron y que se puede recorrer de otra manera para llegar al mismo público, que es el único público posible. Películas familiares, que transmitan un mensaje simple y esperanzador".

10 Rivera, J (2010). Research on Colombian Cinema en Communication Research Trends. Vol. 29, \# 2. Sta Clara University: Santa Clara. La cita en inglés es: "An investigation into Colombian cinema bears a strong resemblance to the cinema production of that country. Both are marked by a general unfamiliarity with what preceded them; both are incipient but more important than the general public estimates; and both lose their impact when fragmented or not communicated to others". Se cita el original que fue escrito en español.

11 De Hoyos, A (2013). Diez años no es nada. Publicado online Domingo, 28 de julio de 2013 en el diario El Espectador. Recuperado el 15 de febrero de www.elespectador.com 
El éxito comercial de sus películas contrasta, no obstante, con la posición de críticos y analistas, quienes plantean que su cine aleja el público entendedor de las salas. Esta idea se refleja en el comentario de Germán Ossa, crítico de cine $^{12}$, cuando afirma que sus películas "no le aportan nada a la formación de públicos con sus terribles cintas, tienen la capacidad de dañar a directores talentosos".

\subsection{Prestigio del cine colombiano en el exterior}

El cine nacional tiene cada vez más presencia en los festivales y muestras más importantes del mundo y la buena calidad de algunas películas le ha ido construyendo un prestigio fundamental como precedente para su avance.

Desde el Ministerio de Cultura se hace énfasis permanentemente en la importancia de que las películas colombianas sean presentadas en los principales festivales del mundo. Desde 2010, más de 125 películas y proyectos han participado en festivales, mercados y talleres de talla mundial. En 2013 la industria cinematográfica nacional se llevó 30 premios de la escena internacional. En la práctica, no obstante, obtener premios no impacta significativamente en la taquilla.

\subsection{Mala relación con el público}

El escritor Luis Tejada13 escribió en 1922: "Para la mayoría de las gentes una novela realista es, con razón, lo más aburridor que hay en el mundo; porque la mayoría de la gente ama lo absurdo posible, lo inverosímil real. Y como no lo encuentra en los libros, va a buscarlo al cinematógrafo, donde se presenta bajo las formas más sencillas, fuertes y exaltantes". Casi 100 años después esta sabia frase tiene mucha más vigencia que entonces.

Un amplio sector del público ve con malos ojos las películas colombianas y habla mal de su cine con base en el conocimiento de muy pocos títulos. La culpa, por supuesto, no es solo del público. La mala relación se basa en experiencias anteriores con películas de mala calidad, problemas de exhibición y falta de formación de públicos. No se puede hablar de divorcio, porque este matrimonio nunca ha existido realmente. Para el director caleño Alexander Giraldo (director de 180 segundos), la conquista de la audiencia es un misterio. Giraldo señala que "Hay que entender que hacemos parte de una cinematografía muy joven. Algunos argumentan que había mucha temática de violencia en las películas, pero en realidad es un cliché, porque si uno se fija cada vez hay más variedad. Si bien muchas plantean conflictos sociales, también hay temas amables"14.

La asistencia del público a la salas es causa de controversia, pues mientras Adelfa Martínez, Directora de Cinematografía de Colombia, explica que el cine cada vez tiene más competencia (Internet, televisión digital y piratería, entre otros) ${ }^{15}$, Julio Luzardo plantea

12 Op. Cit.

13 Tejada, L (1992). Mesa de redacción. Colección de periodismo. Editorial Universidad de Antioquia: Medellín.

14 Entrevista en el diario El País de Cali, julio 15 de 2003.

15 Artículo "Sí vale la pena apoyar el cine nacional" publicado en la revista Semana el 28 de enero de 2014 
que en 10 años la asistencia a cine en Colombia pasó de 17 millones de espectadores al año a más de $41^{16}$.

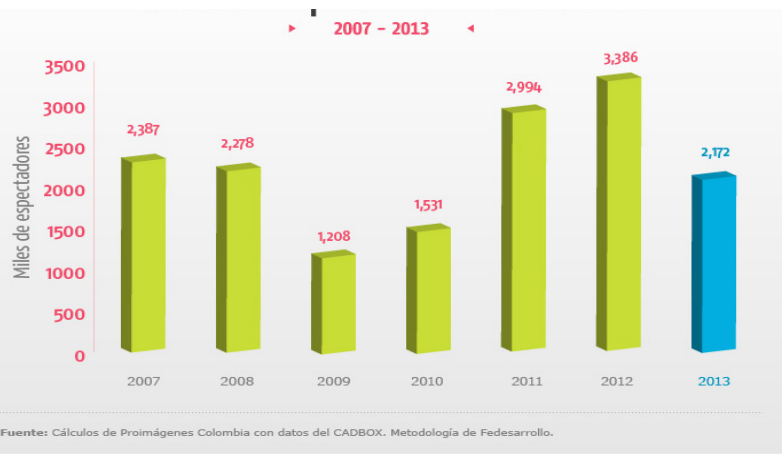

Gráfico 3. Asistencia a películas colombianas.

Fuente: Pantalla Colombia

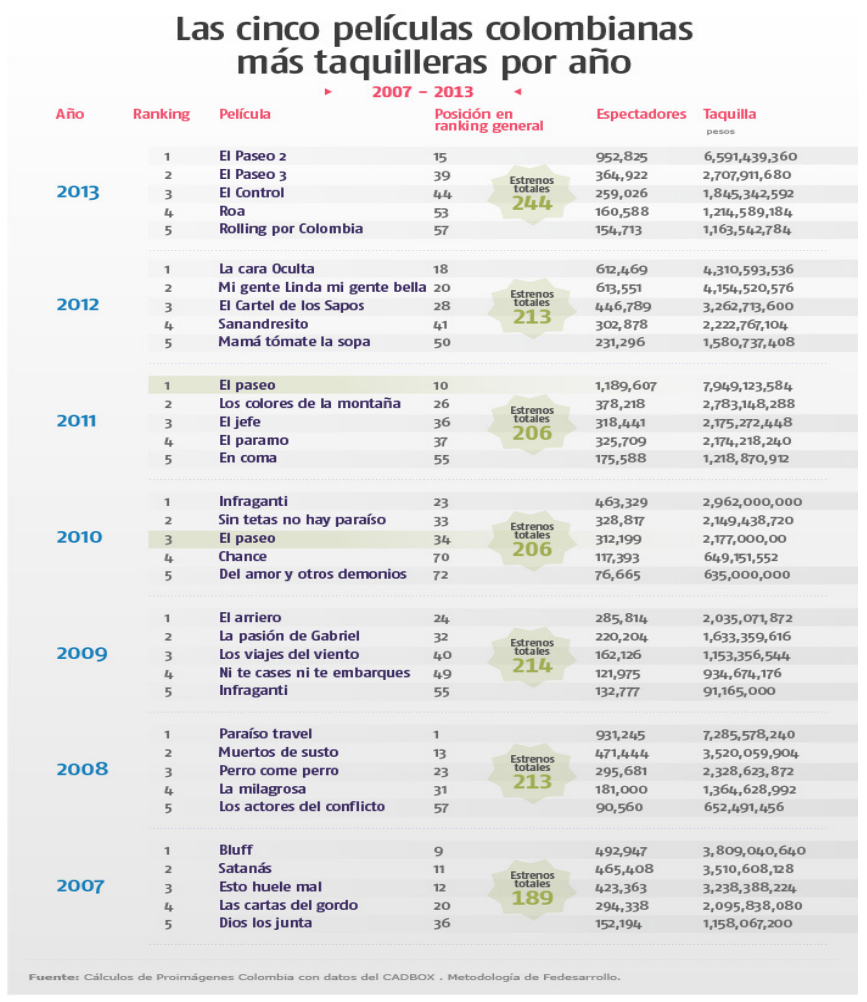

Gráfico 4. Películas colombianas más taquilleras de los últimos años. Fuente: Proimágenes Colombia

16 Artículo "2013 un año difícil para el cine colombiano" publicado en Cinecolombiano.com el 10 de enero de 2014 www.cinecolombiano.com 
Una discusión de vieja data es la que afirma que el cine colombiano exalta la violencia y que este tema es el único que hace parte de la trama de las películas. En una investigación realizada en la Universidad de La Sabana se llegó a la conclusión de que "Aunque se presume que se han hecho más de 600 largometrajes en el país, solo se tienen datos de, aproximadamente, 280 . De estas 280 películas solo el $18 \%$ tiene una temática violenta como principal hilo conductor. Sin embargo, entre las 30 películas más taquilleras del cine nacional, 14 tienen una historia basada en el narcotráfico o el conflicto armado colombiano. ¿Será que todo el cine colombiano es violento o solo que este ingrediente es el que mejor se vende?"17

El reconocido director Víctor Gaviria, uno de los más importantes exponentes del cine que retrata la problemática de la violencia en Colombia, plantea que "El cine tiene la obligación-ya que la televisión comercial no lo hace- de darle un sentido a esa violencia"18. La relación del espectador actual con el cine pasa más por el entretenimiento que por la cultura, como afirma Oswaldo Osorio, "Detrás de los reclamos que se le hacen al cine colombiano reciente es posible identificar un menosprecio por el cine, como parte de un proceso más general de menosprecio por la cultura y el pensamiento. La sociedad del entretenimiento que es ya una realidad que sería patético objetar reivindica una memoria frágil: el mundo aparece como un hecho dado que es inútil explicar o resistir"19.

Si partimos de la base de lo costoso que es hacer cine en Colombia (entre 500 mil y 4 millones de dólares), cada película requeriría tener alrededor de 500 mil espectadores para recuperar su inversión. No son muchas las películas colombianas que lo han logrado. La solución puede consistir en hacer películas con presupuestos más modestos o diversificar más el mercado, pues las películas colombianas suelen morir después de su efímero paso por la cartelera.

\subsection{La exhibición y la distribución}

El monopolio de las salas de parte de las seis "majors" norteamericanas (Fox, Columbia, Paramount, Disney, Warner y Universal) es abrumador. Como en todo el mundo, las salas colombianas se llenan de películas de altos presupuestos y efectos, producidas por grandes estudios que acaparan la taquilla. La Ley no establece algún tipo de protección o incentivo a las salas que proyecten cine colombiano, y las posibilidades de intercambio de películas entre los países latinoamericanos son escasas. A esto se suma que las compañías de exhibición no dan al cine colombiano la oportunidad de recaudar suficiente dinero en taquilla al impedirles pasar a las películas, en muchas ocasiones, del primer fin de semana. En otras ocasiones, se relegan a salas poco representativas u horarios complicados para el público.

17 Rivera, J (2012) Reflexiones sobre la imagen en el cine colombiano en revista Razón y Palabra, Vol. 16, \# 78. Tecnológico de Monterrey- México DF

18 Víctor Gaviria en La realidad, la ficción, la ficción, la realidad. Kinetoscopio N. ${ }^{\circ} 48$. Centro Colombo Americano. Medellín. 1998.

19 Op. Cit. 
La alternativa a esta presencia avasalladora del cine de Hollywood no tiene recetas, pero sorprende que no se hagan más esfuerzos encaminados a la creación de mercados comunes cinematográficos en América Latina, que tiene un potencial de más de 500 millones de personas con un idioma común.

El tema de la circulación de las películas en el país es bastante complicado, pero común a los países de América Latina. Basta con tener en cuenta que en Colombia hay 690 pantallas ubicadas tan solo en el 4 \% del país, pero que el 75 \% de ese índice está ubicado especialmente en Bogotá, Cali, Medellín y Barranquilla y, peor aún, la mitad de ese $75 \%$ está en la Capital del país (ver gráficos 5 y 6).

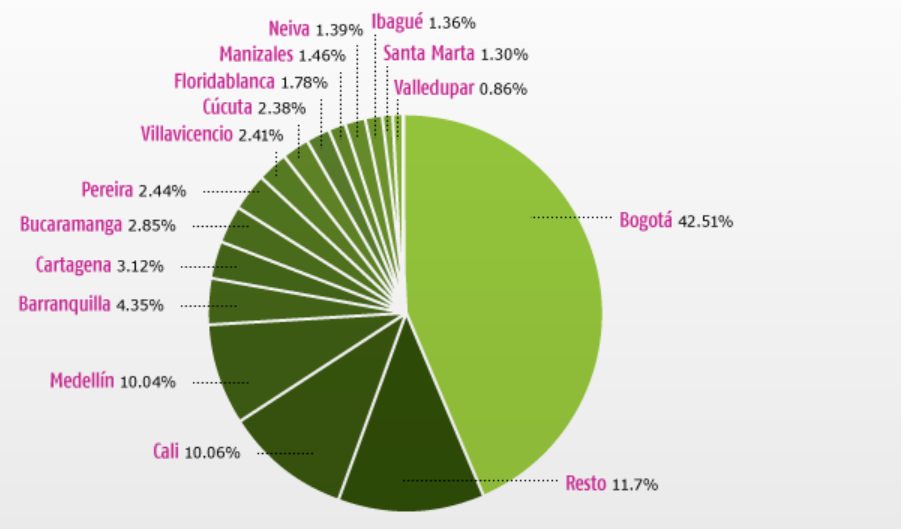

Gráfico 5. Participación del mercado por ciudades.

Fuente: Proimágenes Colombia.

- 2007-2013

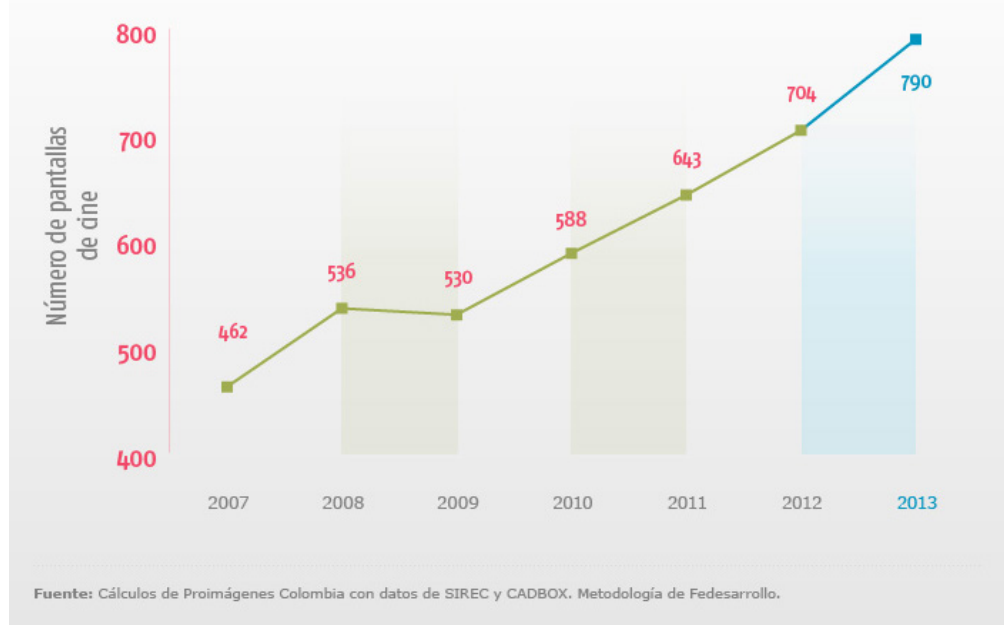

Gráfico 6. Pantallas de exhibición en Colombia.

Fuente: Proimágenes Colombia. 
Para Johny Hendrix Hinestroza (director de la película Chocó), a pesar de que la Ley de Cine ha permitido fortalecer el sector en su profesionalización, faltan muchas cosas, entre ellas mirar el proceso de distribución y promoción de las películas. Afirma que "Mientras la producción de películas es una puerta amplia, la distribución se convierte en una ventana muy pequeña. Si bien hay la impresión de que los distribuidores son los únicos beneficiados, pienso que más allá de que eso, lo que sucede es que no hemos aprendido a usar esa ventana de la distribución bien ${ }^{20 "}$.

La creación de salas de cine alternativas que presenten contenido independiente nacional e internacional puede ser otra buena solución. Tal como se hace en otros países, el Estado podría promover un circuito de salas alternativas que no tengan necesidad de retribución económica.

\subsection{Rentabilidad}

Los logros alcanzados en estos años han sido significativos pues, entre otras cosas, se han recaudado $\$ 73$ mil millones para la industria y el sector privado ha invertido $\$ 100$ mil millones a través de los estímulos tributarios a inversionistas. Esto ha permitido, como ya se ha dicho, que el promedio de películas realizadas en el país sea mayor. El problema es que el número de espectadores no crece significativamente y esto hace que todas las películas deban competir en igualdad de condiciones por la misma franja del mercado.

Es un hecho que el cine en Colombia, y en la mayoría de los países no industrializados, no es rentable. Hacer películas es una inversión de riesgo que puede ser o no rentable dependiendo de la cantidad de espectadores que vayan a ver la película. Silvia Echeverri, directora de la Comisión Fílmica Colombiana señala que los subsidios para el cine son importantes porque es dinero que no hay que devolver y que, sumado a los incentivos tributarios logran que el riesgo del inversionista se reduzca sustancialmente porque él puede reducir de su renta 65 por ciento más de lo que realmente invirtió. De todas formas, los productores deben ser realistas al calcular el público potencial de cada película, pues el mercado cinematográfico colombiano suele ser de miles y no millones de espectadores. En el Foro sobre diez años de cine colombiano organizado por la revista Semana, el crítico Mauricio Reina ha afirmado que los cerca de 44 millones de dólares que ha recaudado el FDC en una década no superan el presupuesto de una sola producción mediana de Hollywood. (Gráfico 7).

\subsection{Los cortometrajes}

Cuando se hacen discusiones alrededor del cine suele olvidarse el cortometraje, parte fundamental de la industria no solo como escuela de realizadores sino como narración corta que, en sí misma, también es un relato cinematográfico complejo y expresivo. Esta reflexión ha suscitado informes especiales, investigaciones y textos académicos como los prestados por la revista Kinetoscopio en su dossier de 2011 denominado "La larga travesía del corto colombiano".

20 Entrevista en el diario El País de Cali, julio 15 de 2003. 


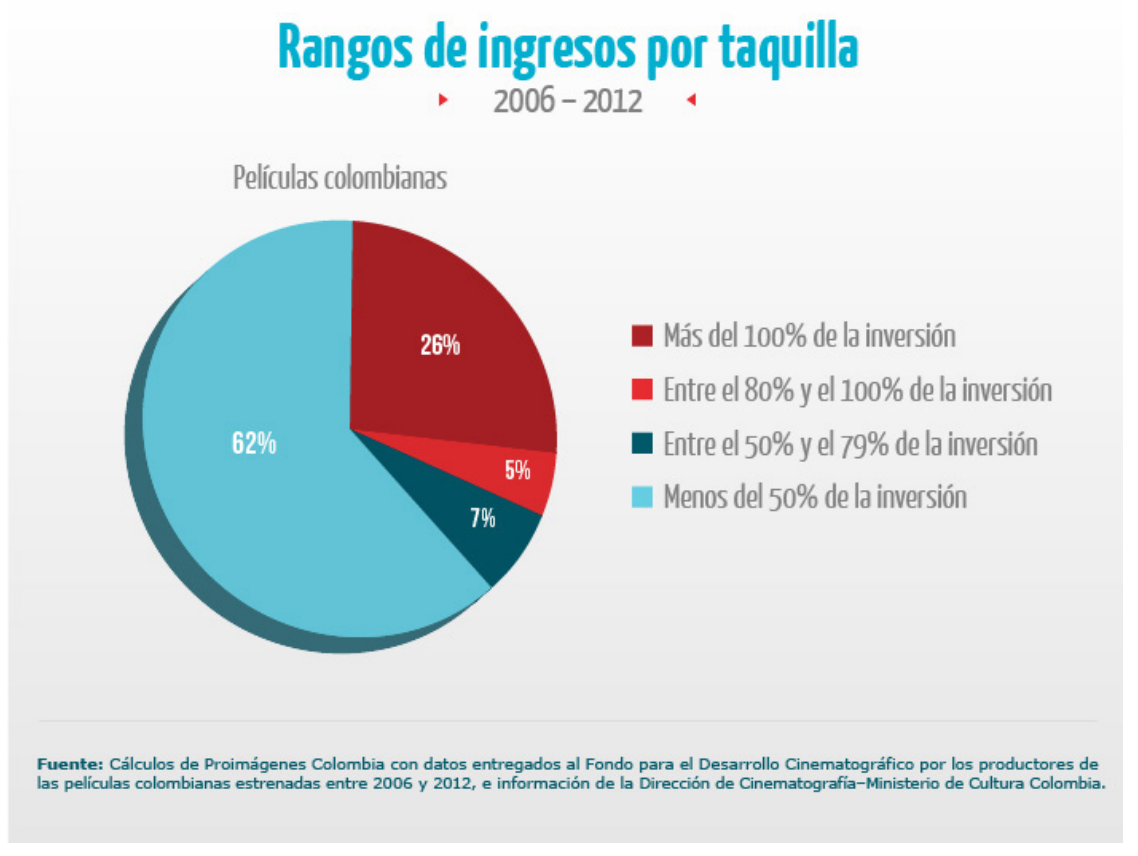

Gráfico 7. Rentabilidad del cine colombiano.

Fuente: Proimágenes Colombia

Desde la época del sobreprecio ${ }^{21}$, el cortometraje ha pasado por muchos inconvenientes. Hoy la ley obliga a pasar un cortometraje colombiano antes de cada película de largometraje. Partiendo de la base de que el cine es un negocio y los exhibidores no quieren arriesgarse a perder dinero, es lógico que los cortometrajes que se presentan sean muchas veces los más baratos del mercado, los que ayudan a cumplir la ley sin hacer un mayor esfuerzo. Como puede verse en el gráfico 8, en ocasiones más de la mitad de los cortometrajes que han sido realizados con dineros del Fondo para el Desarrollo Cinematográfico no llegan a presentarse nunca en las salas (ni hablar de los que se producen de manera "independiente"). Esta situación, no obstante, no es más crítica que la de países como Argentina y México en donde la producción es tan amplia que muchos de los largometrajes nunca son exhibidos.

A esta situación se suma el trato dado a estos productos por parte de los canales de tv que, ávidos por rellenar sus franjas muertas de programación y previamente pautadas con los anunciantes, ofrecen sumas ridículas pidiendo en contraprestación la exclusividad de los obras de mayor calidad. ¿Tiene lógica que a un cortometraje que cuesta 50 mil dólares le ofrezcan 2 mil por un contrato exclusivo?

21 Decreto 879 de 1971 que destinaba un "sobreprecio" de cada boleto de cine para apoyar la producción cinematográfica del país, privilegiando la producción de cortometrajes y exigiendo a los exhibidores su presentación al inicio de cada función. 
De todas formas, hoy los cortometrajes tienen una mayor difusión y que se han abierto importantes ventanas nacionales e internacionales gracias a las posibilidades que ofrece Internet. El gran caudal de información disponible en la Red, no obstante, invisibiliza muchos de estos productos. En la gráfica 5 se aprecia la cantidad de cortometrajes apoyados por el FDC y cuántos han sido exhibidos en pantallas.

\section{Cortometrajes colombianos registrados en el Ministerio de Cultura y exhibidos en pantallas \\ , $2007-2011$}

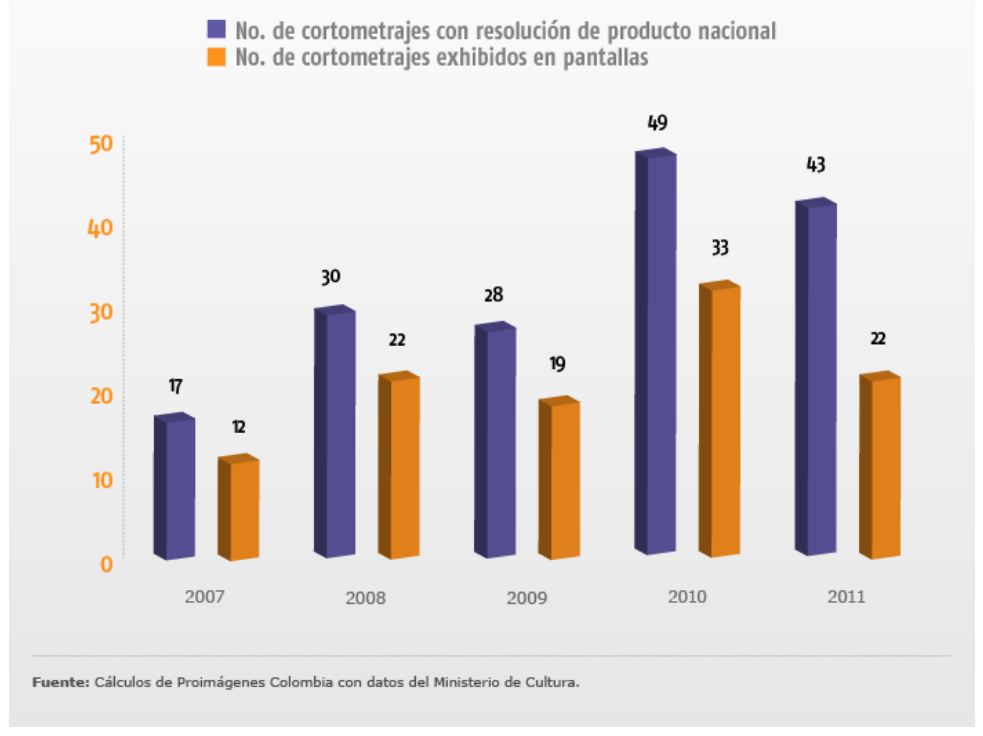

Gráfico 8 cortometrajes realizados y exhibidos.

Fuente: Proimágenes Colombia

\section{Conclusiones}

Haciendo un balance de todos los aspectos anteriormente mencionados, es claro que la Ley 814 de 2003, Ley de Cine, tiene más aspectos positivos que negativos. Lo que aún no funciona bien es realmente una oportunidad para mejorar y, en muchos casos, se trata de la inmadurez natural de un sector "adolescente". Hace algunos años, en un foro con productores latinoamericanos, Jack Valenti, Presidente de la MPAA, mencionó "En una época el mundo descubrió que nosotros hacíamos los mejores aviones y decidieron dejar de producirlos para comprarlos a los que saben. Nosotros sabemos hacer películas, ¿Para qué insisten ustedes en hacerlas?". La respuesta a esta pregunta es muy clara: para no olvidar quienes somos y contar nuestras propias historias.

Por muchos años se dijo que nuestro cine estaba en pañales y al parecer por fin los ha dejado. El cine colombiano actual es ambivalente: presenta algunas buenas historias 
y algunos clichés; explora nuevas técnicas y temáticas, pero no obtiene suficientes ganancias; gana premios en festivales de cine, pero su público aún no le cree. Nuestro cine, como cualquier adolescente, todavía tendrá algunos años para superar esta amarga época de decepciones amorosas e inseguridad, ocultar el acné y soportar los cambios hormonales. De nosotros los colombianos depende que algún día pueda ser un adulto orgulloso de sus logros.

\section{Bibliografía}

De Hoyos, A (2013). Diez años no es nada. El Espectador. Domingo, 28 de julio de 2013. Recuperado el 15 de febrero de http://www.elespectador.com/noticias/cultura/diez-anos-no-nada-articulo-436319

Gaviria, V (1998). La realidad, la ficción, la ficción, la realidad. Kinetoscopio No 48. Medellín: Centro Colombo Americano.

Luzardo, J (2014). 2013: Un Año Difícil Para el Cine Colombiano. Cinecolombiano.com recuperado el 1 de febrero de 2014. http://cinecolombiano.com/2013-un-ano-dificil-para-el-cinecolombiano/\#more-3091

(2013). Cine colombiano: ¿Exceso de paternalismo? Cinecolombiano.com. 24 de noviembre de 2013. Recuperado el 20 de enero de 2014. http://cinecolombiano.com/cine-colombiano-excesode-paternalismo/

Moncada, R (2013). La Ley que hizo florecer el cine colombiano. Gaceta-El País. Julio 15, 2013.

Montoya, J (2013). A 10 años de la Ley de Cine. El Colombiano. Recuperado el 4 de octubre de 2013. http://www.elcolombiano.com/BancoConocimiento/A/a_10_anos_de_la_ley_de_cine/a_10_anos_ de_la_ley_de_cine.asp

Osorio, O. Cine colombiano: iSe busca! Recuperado el 24 de enero de 2014. www.cinefagos.net

(2013). 10 años de la ley de cine: Las cifras y sus matices. Guion Actualidad recuperado el 4 de diciembre de 2013. http://guionactualidad.uab.cat/?p=4992

Reina, M (2013). Análisis sobre el significado de esta ley. Portafolio. Recuperado el 3 de diciembre de 2013. www.portafolio.com.co

Rivera, J (2012) Reflexiones sobre la imagen en el cine colombiano. Razón y Palabra, Vol. 16, \# 78. México DF: Tecnológico de Monterrey.

(2011). Reflexiones sobre el cortometraje en Colombia en La larga travesía del corto colombiano Revista Kinetoscopio \# 94. Medellín: Centro Colombo Americano.

(2010). Research on Colombian Cinema en Communication Research Trends. Vol. 29, \# 2. Sta Clara University: Santa Clara.

- Tejada, L (1992). Mesa de redacción. Colección de periodismo. Medellín: Editorial Universidad de Antioquia.

\section{Artículos de prensa:}

Sí vale la pena apoyar al cine nacional. Semana. Recuperado el 14 de febrero de 2014. http://m.semana. com/cultura/articulo/si-vale-la-pena-apoyar-el-cine-nacional/372293-3

Especial 10 años de la ley del cine. Semana. Recuperado el 14 de febrero de 2014. http://www.semana. com/cultura/multimedia/especial-10-anos-de-la-ley-del-cine/368072-3

Cine colombiano, no es rentable pero promete. Dinero. Julio 9, 2013. Recuperado el 22 de agosto de 2013. http://m.dinero.com/actualidad/nacion/articulo/cine-colombiano-no-rentable-peropromete/179310 
Diez años después de la Ley de Cine colombiana. Agencia de Noticias UN. Bogotá: jul. 24 de 2013.

Cineastas siguen quedando en la quiebra para cumplir el sueño de hacer cine. Señal Radio Colombia. 16 Julio 2013.

Historia de un fracaso. Después de 15 años de experimentos, el cierre de Focine convence a muchos de que no debe haber cine colombiano. Semana. 1 de marzo de 1998.

Pantalla Colombia. Sitio web: www.pantallacolombia.com 